INVESTIGACIONES

de HISTORIA ECONÓMICA

IHE. Otoño 2009. Pp. 75-108

\title{
La expansión "por defecto" del estado empresario. La política económica frente a la crisis de las empresas industriales en la Argentina, 1960-1976
}

\section{The expansion "by default" of the state owner. The policy economic and the industry crisis in Argentina, 1960-1976}

\author{
MARCELO ROUGIER \\ Universidad de Buenos Aires - CONICET
}

\begin{abstract}
RESUMEN
En la década de 1960 un conjunto de empresas industriales evidenciaron problemas financieros y productivos. Con el propósito de atemperar estos problemas y en algunos casos "salvar" a esas empresas de la quiebra, sucesivos gobiernos diseñaron un conjunto de medidas, básicamente financieras (como apoyos crediticios especiales, tolerancia y moratorias impositivas). En la segunda mitad de esa década se sancionaría un régimen de ayuda conocido como de "rehabilitación de empresas", que luego fue completado y reformulado con otras medidas legales. Muchas de las firmas que se acogieron a este régimen fueron declaradas en quiebra años después; mientras tanto gozaron de asistencia financiera estatal para continuar su marcha productiva y evitar conflictos sociales, una cara preocupación política de los gobiernos de distinto carácter que se sucedieron en el poder. El artículo analiza la forma particular que adoptó la toma de decisiones de política industrial derivada de presiones puntuales ejercidas por los empresarios y el contexto socio-político de la Argentina en esos años.
\end{abstract}

PALABRAS CLAVE: Industria, Politica económica, Industria, Empresas, Argentina

Códigos JEL: N86

\section{ABSTRACT}

In the sixties a set of industrial companies, many of them with a long trajectory in the markets in which they operated, experienced financial and production problems. In order to solve these problems and in some cases "save" the companies from bankruptcy, successive governments designed a set of measures, basically financial (such as special credit support, tax tolerance and moratoriums). Finally, in the second half of that decade, an aid scheme known as the "company rehabilitation" scheme, which was soon complemented with other legal measures, was sanctioned. Many of these companies were declared bankrupt years later; in the meanwhile they had state financial support to continue their production and to avoid social conflicts; a major political problem for these successive governments that followed one another into power. The article analyzes the particular form adopted by decision making in relation to industrial policies, and the way it originated from the pressure exerted by industrialists and the sociopolitical context of Argentina in those years.

KEY WORDS: Industry, Economic policy, companies, Argentina

JEL Codes: N86 


\section{Introducción}

$\mathrm{E}$ n la primera mitad de la década del sesenta, en parte como consecuencia de la recesión económica de 1962-1963, un conjunto de empresas industriales, muchas de ellas de larga trayectoria y gran importancia en los mercados en que actuaban, evidenciaron problemas financieros y productivos. Con el propósito de atemperar estos problemas y en algunos casos evitar la quiebra de esas industrias, sucesivos gobiernos diseñaron un conjunto de medidas, tales como apoyos crediticios especiales o moratorias impositivas. Finalmente, en la segunda mitad de esa década, luego de que se manifestaran nuevos problemas para las firmas locales, se sancionaría un régimen de ayuda específico, que fue completado y reformulado con otras medidas legales; algunas de las industrias que se acogieron a este régimen no pudieron rehabilitarse y fueron declaradas en quiebra años después; en el ínterin gozaron de asistencia financiera estatal para continuar su marcha productiva y evitar así conflictos sociales, una cara preocupación política por esos años.

En otros términos, la crisis de 1962-63 provocó una grave restricción financiera a un conjunto significativo de empresas y sus problemas debieron ser considerados de allí en más por los hacedores de políticas económicas y sociales, en la medida que esas dificultades no podían imputarse al mal desempeño empresario o a que las unidades productivas no fuesen viables desde el punto de vista económico; más tarde las dificultades de las empresas industriales fueron consideradas por cuanto su quiebra podía acarrear conflictos no deseables en una arena política signada por tensiones e inestabilidades particularmente fuertes a comienzos de los años setenta, previas al regreso de Juan Perón al poder y aún después. La persistencia de esas dificultades condujo a la elaboración de numerosos proyectos y a la sanción de distintas medidas de ayuda financiera, y finalmente a la instrumentación de un régimen denominado de "rehabilitación de empresas" hacia 1967 que se mantendría con variantes hasta 1976.

El tema es particularmente relevante dada la gran cantidad de empresas (alrededor de trescientas) que pretendieron ser incluidas inicialmente en el sistema de ayuda especial, un universo significativamente grande del sector industrial argentino. Asimismo, el hecho de que muchas industrias tuvieran importantes problemas en una etapa de gran expansión y maduración del sector manufacturero en su conjunto es revelador de los múltiples factores que afectaban el desempeño empresarial por aquellos años y que no pueden reducirse a problemas de competitividad o eficiencia productiva, mala conducción empresarial o errores de diseños estratégicos y de implementación. La lógica del ciclo económico argentino y los constantes cambios

[Fecha de recepción del original, 25 de mayo de 2008. Versión definitiva, 4 de febrero de 2009]. 
en las definiciones de política económica en el corto plazo reclaman también parte de la explicación, así como algunos problemas específicos del diseño institucional vinculado al financiamiento de las empresas.

Pese a su importancia, la temática enunciada no ha sido considerada por la historiografía económica argentina. Si bien existen importantes estudios que han focalizado en los problemas del crecimiento industrial en lo que se ha denominado la segunda fase del proceso de industrialización por sustitución de importaciones (1950-1975), estos no han recalado en las dificultades financieras y de mercado de las empresas nacionales, y menos aún en las políticas públicas diseñadas para atenuar esas dificultades o evitar su quiebra. Significativamente, la literatura enfatiza el buen desempeño global del sector industrial en la etapa, particularmente desde mediados de los años sesenta, y hace hincapié en las transformaciones productivas y avances tecnológicos del sector derivadas en parte de los mecanismos de promoción y planes de desarrollo elaborados en la etapa; no obstante, esa bibliografía descuida los efectos que las políticas económicas destinadas a resolver los desequilibrios en el sector externo (devaluaciones) o contener la inflación (políticas monetarias y fiscales restrictivas) provocaron sobre la estructura del sector industrial ${ }^{1}$. Finalmente, los análisis locales no han prestado suficiente atención a la conformación y avance del estado empresario en la Argentina y menos aún lo han hecho respecto a esa expansión como consecuencia de la crisis de numerosas empresas industriales, una "intervención de último recurso" que ha sido estudiada en otras experiencias nacionales, particularmente los casos del Istituto per la Ricostruzione Industriale (IRI) italiano y del Instituto Nacional de Industria español en el continente europeo ${ }^{2}$. Si bien, como se demostrará, la experiencia argentina se aleja decididamente de esos modelos, los estudios disponibles sobre esos casos no dejan de ser sugerentes guías para abordar problemáticas comunes allí donde se tendió a crear instrumentos o mecanismos destinados a "salvar" a las empresas con problemas.

Este artículo tiene dos propósitos principales: por un lado analizar las situaciones que dieron origen a la sanción de la ley de rehabilitación de empresas e interpretar la concepción general que subyace en su diseño e instrumentación. Por otro, señalar las modificaciones y derivaciones que ese instrumento tuvo con el propósito de acercarnos a una evaluación global de sus resultados. Para ello en primer lugar destacamos el impacto que la crisis económica iniciada en 1962 tuvo sobre el con-

Véanse por ejemplo Katz (1967), Gerchunoff y Llach (1975), Dorfman (1983) y Katz y Kosacoff (1989). Sólo Schvarzer (1996) ha incorporado de manera sintética en su análisis sobre la industria del período las dificultades financieras de algunas empresas y la acción estatal destinada a evitar su quiebra.

2 Entre los pocos estudios sobre el estado empresario en la Argentina destacan los de Kaplan (1969), Andrieu (1975), Schvarzer (1979) y Ugalde (1983). Para el caso europeo véanse entre otros Sapelli y Carnevalli (1986), Aceña y Comín (1990), Amatori (2000), Toninelli (2000) y Comín y Díaz Fuentes (2004). 
junto del sector industrial y cuáles eran las demandas específicas de los empresarios en ese particular contexto. Luego analizamos las respuestas instrumentadas desde el Estado para intentar solucionar las dificultades que aquejaban a los industriales; en este sentido, será importante discernir los distintos proyectos e intereses que emanaban desde diferentes ámbitos de la estructura burocrática estatal y el grado de "enraizamiento" con las demandas de los empresarios. En otras palabras, la búsqueda incluirá un análisis de la forma particular que adoptó la toma de decisiones de política industrial en la Argentina derivada de presiones puntuales ejercidas por los empresarios y el contexto socio-político. Finalmente se analizan los avatares del régimen de rehabilitación instrumentado a fines de los años sesenta y se avanza hacia una comprensión integral de sus resultados hacia 1976, cuando la dictadura militar decidió liquidar aquellas empresas que no estaban en condiciones de operar económicamente y privatizar otras que habían quedado por diferentes circunstancias bajo control del Estado.

En suma, este artículo analiza sobre la base de fuentes primarias las dificultades que experimentó el sector industrial en los años de auge y maduración del modelo sustitutivo de importaciones no tanto con el propósito de explicar las causas de esos problemas sino con el de interpretar las definiciones de política industrial de un Estado vacilante a la hora de generar e implementar mecanismos para hacerles frente. Nuestra hipótesis sugiere que el resultado de ese proceso fue la implementación de un régimen de ayuda financiera que se fue modificando sobre la marcha y que tuvo distintos criterios a la hora de definir qué empresas podían incorporarse pero donde predominó, finalmente, una lógica de preservación de la actividad productiva alejada de consideraciones de eficiencia y de desarrollo industrial, estrechamente vinculada al mantenimiento del empleo y a evitar el conflicto social. Paralelamente nuestro trabajo arroja luz respecto a la relación establecida entre los empresarios y el estado, una temática de gran empuje en la literatura económica y social vinculada al desarrollo en los últimos años ${ }^{3}$.

\section{El avance del sector industrial durante la estrategia desarrollista}

En los últimos años de la década de 1940, cuando el peronismo gobernaba la Argentina, la economía local sufrió una crisis de grandes proporciones, cuya manifestación era el estrangulamiento de la balanza de pagos. Esa sería la primera de una serie de crisis periódicas dentro de la dinámica del ciclo stop and go, modelizado años des-

3 Véanse entre muchos otros Evans (1995) y Schneider (2004). 
pués, caracterizado por una crónica insuficiencia de divisas ${ }^{4}$. Los hacedores de política económica respondieron a ese desafío tratando de impulsar las actividades agropecuarias y, en consecuencia, los saldos exportables; paralelamente se decidió avanzar en el proceso de sustitución de importaciones y ahorrar divisas con una mayor integración del sector manufacturero. La estrategia era difícil, en ese particular contexto internacional y de la política local, dada la necesidad de recurrir al capital extranjero para impulsar inversiones en industrias de base y otras actividades claves para el desarrollo económico. Las resistencias políticas al abandono del nacionalismo económico que supuestamente había caracterizado al peronismo frustrarían más de un proyecto de inversión. De todos modos, el conjunto de medidas destinado a resolver los problemas comentados fue relativamente exitoso y la economía argentina se recuperó entre 1953 y 1955. Pero el conflicto político dominó el escenario en esos años y condujo finalmente al golpe militar. La llamada "Revolución Libertadora" convocó al prestigioso Raúl Prebisch para que asesorara al gobierno y elaborara un plan económico. Prebisch destacó los problemas del crecimiento de la economía argentina y básicamente propuso avanzar en la integración del sector industrial, profundizando la sustitución de importaciones, más allá de algunas medidas de corto plazo destinadas a mejorar los precios del agro y obtener divisas para paliar la coyuntura, por cierto escasamente populares. Pero fue el gobierno de Arturo Frondizi a fines de esa década el que pronto manifestó su decisión de atraer sin ambages al capital extranjero, una práctica que también se aplicó en otros países latinoamericanos por ese entonces. En particular, la estrategia desarrollista ponía énfasis en el área petrolera con el propósito de reducir el gasto de divisas en ese rubro, en la producción de automóviles y en la industria química. Una ley de inversiones extranjeras sancionada en diciembre de 1958 permitió el ingreso de numerosas empresas al mercado local y en los dos años siguientes se aprobaron 138 propuestas de radicación de capitales extranjeros por un valor de 271 millones de dólares 5 . El 90\% de esas inversiones se concentraron en los sectores petroquímico, de transportes, metalúrgico y de maquinaria (en particular en la producción automotriz). Paralelamente, una ley de promoción autorizó al Poder Ejecutivo a tomar medidas vinculadas a la liberación de derechos y recargos y a la política cambiaria para facilitar el equipamiento.

El ingreso de las firmas transnacionales al escenario local y la conformación de una especie de "polo industrial moderno" con un uso relativamente alto del factor capital no supuso necesariamente el desplazamiento de las empresas nativas en tanto las inversiones se dirigían hacia sectores donde no existía producción nacional

Existe una amplia literatura sobre la dinámica de las crisis recurrentes del sector externo de la economía argentina en la posguerra; análisis contemporáneos pueden encontrarse en Ferrer (1963), Prebisch (1963) y especialmente Braun y Joy (1968).

$5 \quad$ Schvarzer (1996), p. 227. 
o esta era escasa ${ }^{6}$. Por el contrario, muchas industrias locales apostaron por ampliar su producción y abastecer -en un proceso de creciente integración a las empresas extranjeras de productos semi-terminados (semi-elaborados) insumos; algunas optaron también por realizar contratos con firmas del exterior para producir bienes bajo licencia y recibir generosos créditos en divisas. No obstante, también es cierto que algunas empresas productoras de máquinas herramientas u otros bienes de capital sufrieron la competencia internacional producto de la política de apertura para este tipo de bienes que impulsó el gobierno.

\section{La crisis de 1962-1963: ajuste macroeconómico y dificultades empresariales}

Se ha señalado que la crisis que sufrió la Argentina en 1962-1963 resultó ser una caída más dentro de la secuencia cíclica del desempeño económico en el modelo sustituti$\mathrm{vo}^{7}$. Esta crisis fue de corta duración pero particularmente intensa en el sector industrial, afectando las cuentas patrimoniales de un conjunto importante de empresas por varios años; esta situación condicionaría a su vez las definiciones respecto al sector industrial de los sucesivos gobiernos en el resto de la década y aún en la siguiente.

La crisis puede presentarse en un análisis de mediano plazo de la evolución de la economía argentina. El lustro que transcurre entre 1959 y 1963, mirado entre puntas, refleja un estancamiento del producto y las importaciones. Por el lado de la demanda el consumo cayó, la inversión creció al 1,5\% anual y las exportaciones más del 6\% anual. No obstante este desempeño global, el comportamiento fue extremadamente errático en el período: en 1959 el plan de estabilización del gobierno provocó una fuerte caída de todas las variables macroeconómicas con excepción de las exportaciones; 1960 y 1961 fueron años de expansión con importantes tasas de crecimiento (de hecho, el incremento del producto en 1960 fue el mayor desde 1947), donde descolló la inversión (47\% y 10\% de aumento respectivamente) impulsada en gran medida por generosos créditos de proveedores extranjeros. Finalmente, en 1962 y 1963 la recesión castigó a la economía local y todas las variables tuvieron un comportamiento negativo con excepción de las exportaciones.

La situación externa era inicialmente holgada sólo porque existía financiamien-

to; pero el déficit comercial comenzó a crecer paralelamente a la reactivación dentro

\footnotetext{
6 La expresión "polo industrial moderno" relacionado con la implantación de empresas extranjeras en la Argentina se encuentra en Gerchunoff y Llach (1975), p. 5.

7 Ferrucci (1991); Rapoport (2003); Gerchunoff y Llach (1998).
} 
de la lógica de la fase de auge de la secuencia cíclica, situación que se agravó con la pálida cosecha de 1960-1961. La composición de las importaciones reflejó las decisiones de política económica del gobierno: la compra de combustible en el exterior se derrumbó, también cayeron las importaciones de bienes de consumo, mientras que las de bienes de capital registraron un fuerte aumento, en particular la importación de maquinarias cuya participación sobre el total pasó de 26 \% en 1958 a más del 40\% en 1960 y 1961.

La reducción de las reservas y el mantenimiento de un tipo de cambio fijo provocaron una importante reducción de la liquidez en el mercado. A fines de 1961 la demanda agregada perdió vigor y muchas empresas comenzaron a tener dificultades de colocación en un contexto de restricción crediticia y altas tasas de interés. A partir de entonces se ensayaron algunas medidas de emergencia como la reimposición de aranceles, eliminación de retenciones y restricciones a las importaciones de las empresas públicas. De todos modos, el escenario parecía estar determinado por el proceso político. El clima se enrareció aún más con la derrota electoral del oficialismo a fines de 1961 que preanunció un nuevo colapso institucional.

En abril de 1962, con el derrocamiento de Frondizi, la ortodoxia monetaria se profundizó de la mano de Federico Pinedo, primer ministro de Economía del presidente José María Guido. El experimentado funcionario liberó el mercado cambiario y como consecuencia se desató una "corrida" que elevó el precio del dólar de 83 a 132 pesos por unidad. La devaluación provocó un incremento de los precios de los bienes transables, e implicó un aumento significativo de los costos de producción de las firmas industriales a la vez que un deterioro del poder adquisitivo de los salarios. La situación negativa se agravó por la política fiscal (congelamiento de salarios, diferimientos en los pagos a proveedores y trabajadores), el aumento de los impuestos al consumo y de las tarifas de los servicios públicos. A pocos días de haber asumido, Pinedo renunció y fue reemplazado por Álvaro Alsogaray que continuó con las políticas fiscales restrictivas y recurrió a la emisión de bonos para el pago a proveedores y asalariados. También la política monetaria se encaminó a la ortodoxia y acentuó los efectos recesivos al incrementar las tasas de interés. Los dos últimos ministros de Guido, Eustaquio Méndez Delfino y José Martínez de Hoz sólo atinaron a flexibilizar parcialmente la política monetaria y a limitar las importaciones del sector público (con un régimen de "compre argentino") con el fin de "administrar" la crisis y mejorar la posición de la balanza de pagos ${ }^{8}$.

La política cambiaria, fiscal y monetaria provocó graves consecuencias sobre el sector productivo, en especial sobre la producción manufacturera que cayó un 5,5\% en 1962 y un 4\% al año siguiente, luego de haber crecido a un ritmo cercano al 10\% 
anual en el bienio anterior. La capacidad ociosa del sector (calculada en 56\%) se reflejó en una desocupación de casi el 9\% para 1963. En especial, la fuerte devaluación de 1962 produjo un destacado impacto sobre la actividad económica nacional dado que el sector privado y el público se habían endeudado de manera importante en el exterior durante los años anteriores. La reducción de la demanda efectiva agravó las necesidades financieras de las empresas en un contexto de iliquidez e incidió directamente en su nivel de producción, impidiendo, en los casos en que no fueron directamente a la quiebra, la utilización plena de la mayor capacidad de elaboración lograda a través de su reequipamiento anterior ${ }^{9}$.

Las quiebras comerciales que habían sido 800 en 1960 aumentaron a 1.300 en 1961, a 1.800 en 1962 y a más de 2.500 en 1963. El ministro de Economía admitió que el deterioro era ya "irreversible para un número indeterminado de empresas (...) muchas caídas no volverán a levantarse ${ }^{\prime 10}$. Recién en el segundo trimestre del año 1963 comenzaría una pequeña reactivación general que a favor de la normalización institucional con la asunción del gobierno constitucional de Arturo Illia mejoró las expectativas empresarias y produjo una reacción positiva del sector manufacturero.

\subsection{Después de la crisis. La trascendencia de los problemas de SIAM}

Las variables macroeconómicas mejoraron claramente a partir de 1964, año en que se inició un proceso de crecimiento industrial ininterrumpido hasta 1975. La industria en su conjunto tuvo tasas de crecimiento superiores al $7 \%$ anual promedio en ese período y todos los sectores, incluso los productores de bienes no durables, tuvieron un comportamiento expansivo; paralelamente se verificó un proceso de creciente sofisticación técnica y capacidad exportadora de un conjunto importante de empresas que reflejó el grado de maduración alcanzado por la industria argentina en esos años. No sólo las grandes empresas extranjeras, sino también las empresas medianas de las ramas dinámicas y las grandes empresas de las ramas vegetativas, independientemente de su nacionalidad tuvieron un comportamiento expansivo en la segunda mitad de la década de 1960.

No obstante esa expansión, un conjunto de firmas locales resultó, al menos inicialmente, afectado fuertemente por la crisis económica de 1962-1963 y por un nuevo problema, la competencia de las empresas extranjeras radicadas en el país durante la experiencia desarrollista. Muchas empresas que sobrevivieron a la crisis encontraron

9 Banco Industrial de la República Argentina (BIRA, en adelante), Memoria y Balance, 1963, p. 7.

10 Citado en "Resultados de una acción sin concierto y perspectivas", Boletín de la Unión Industrial Argentina, enero-mayo de 1963. 
dificultades para crecer desplazando a competidores y la búsqueda de nuevos consumidores se tornó decisiva ${ }^{11}$. De todos modos, debe destacarse que las empresas no fueron perjudicadas de igual manera; tampoco sus estrategias para enfrentar los efectos perniciosos derivados de la devaluación y recesión fueron similares. En ello pesaron las políticas empresariales previas y las capacidades productivas, organizacionales y de comercialización desarrolladas; también debe considerarse la pertenencia de ciertas empresas a conglomerados que les permitieron capear las restricciones financieras o incorporar con mayor facilidad los avances tecnológicos. En rigor, cada caso tenía su especificidad y algunos eran por lejos más trascendentes y de mayor impacto productivo y social, lo que fue advertido rápidamente por los funcionarios estatales.

Hacia 1965 el secretario de Industria del gobierno radical estaba particularmente preocupado por la situación financiera de la Sociedad Industrial Americana de Maquinarias (SIAM). Esta firma había iniciado un proceso de fuerte expansión a fines de los años cincuenta con el objetivo de producir equipo eléctrico para locomotoras y automóviles aprovechando una serie de estímulos que había brindado el gobierno de Frondizi. Esas inversiones se financiaron en una parte importante con créditos del Eximbank, avalados por el Banco Industrial de la República Argentina (BIRA) ${ }^{12}$.

Poco tiempo después de encarados estos proyectos, SIAM debió enfrentar diversos problemas derivados en parte de los cambios comentados en la política económica del gobierno nacional que afectaban a toda su actividad. La recesión económica de 1962 provocó que las distintas plantas de la firma trabajaran a la mitad o menos de su capacidad normal mientras que la empresa madre, que había contraído grandes obligaciones en el exterior para financiar las inversiones y gastos operativos atravesaba una difícil situación financiera. Las sucesivas modificaciones del tipo de cambio repercutieron en forma directa en los costos financieros y productivos de la empresa ${ }^{13}$. Los directivos explicaban las dificultades por la restricción del crédito bancario y la virtual desaparición del mercado de capitales frente a las demandas derivadas de la contracción del mercado, el deterioro de las cobranzas — tanto al Estado como al sector privado-, y los impactos de la fuerte y continua desvalorización del peso ${ }^{14}$.

Pero la empresa también tenía problemas productivos y de mercados en la fabricación de electrodomésticos y en el rubro automotor. En el primer caso la empresa se veía afectada por la competencia y la caída del mercado interno y el hecho de que la

Gerchunoff y Llach (1975), p. 8.

Un estudio detallado de la crisis de esta empresa en Rougier y Schvarzer (2006), primera parte.

SIAM Di Tella Ltda., Memoria y Balance, 30 de junio de 1963.

SIAM Di Tella Ltda., Memoria y Balance, 30 de junio de 1966. 
reposición por obsolescencia física no había llegado a impulsar la demanda luego de la explosión de compras de los años cincuenta.

En el rubro automotor, el ingreso de firmas extranjeras a partir de 1960 desencadenó en ese mercado una feroz competencia que se vio agravada por los efectos de la profunda crisis económica que sobrevino poco después de lanzada la actividad, en 1962-1963. Como se señaló, esa crisis no sólo afectó la producción automotriz sino también las ramas de bienes de consumo durables, que formaban por entonces los sectores decisivos de la producción de la empresa (la producción de Automotores se redujo a la mitad en 1962 respecto a 1961). Luego de algunos acuerdos de complementación, la planta fue finalmente vendida a la empresa Kaiser Argentina (IKA).

Empero, los problemas de contexto, de mercado y productivos no eran la única causa de la crisis. La responsabilidad del grupo director de SIAM en la inversión en nuevas y numerosas actividades que se encontraban sujetas a los vaivenes de la política estatal y que planteaban un riesgo apreciable producto de la inestabilidad institucional es evidente. La dirección empresarial subordinó su expansión principalmente a la dinámica de la inversión pública y a los contratos que pudiera obtener de las reparticiones estatales. Asimismo, las inversiones fueron financiadas a través de un endeudamiento constante, en el exterior y en el mercado interno, a plazos muy cortos. Estas deudas generaban un riesgo cambiario (para la deuda en divisas) y un riesgo de liquidez (por la exigencia de renovar continuamente la deuda de corto plazo) que terminarían por generar una crónica fragilidad financiera. Como una de las respuestas a estos problemas la empresa, al igual que muchas otras, tendió a diferir todo lo posible el pago de las cargas sociales e impositivas, método que surgió como una alternativa para financiar sus operaciones corrientes.

Hacia 1965, los empresarios realizaron una serie de gestiones ante la Secretaría de Industria para lograr una refinanciación conjunta de todas las deudas; se realizaron acuerdos con más de quince entidades para lograr refinanciar y consolidar de modo general las deudas (unos 34 millones de dólares) a veinte años de plazo. Pero las negociaciones de las obligaciones con el Estado seguían siendo complejas. Los organismos acreedores actuaban muchas veces en forma independiente y celosamente cuidaban su caja. El problema impositivo de SIAM era quizás el de mayor dificultad. Las deudas con la Dirección General Impositiva (DGI), por impuestos a los réditos y a las ventas, principalmente, se habían originado en 1960. En 1966 la empresa dejó de pagar todos sus compromisos a la espera de una negociación global de la deuda acumulada de las filiales y el holding.

SIAM presentó un plan al gobierno radical donde solicitaba unos 10 millones de dólares "de plata fresca" y una financiación a muy largo plazo (hasta veinte años) de todas las deudas. La actitud del gobierno fue positiva, pero ésta era sin duda una solución que debía considerarse "excepcional" y resolverse en el plano más estrictamente político. 


\section{Las alternativas de un estado marcado por la inestabilidad política}

El caso SIAM involucraba a la mayor empresa industrial de la Argentina y fue en gran medida el que motorizó una serie de debates, proyectos y reglamentaciones en los años subsiguientes. El secretario de Industria del gobierno radical, Alfredo Concepción, tenía una opinión favorable respecto a la solicitud de la empresa; por un lado juzgaba su importancia en el mercado y por otro su trayectoria: "ahí había un esfuerzo concretado de mucha envergadura que de ninguna manera podía ser desperdiciado", señalaba; aunque también visualizaba problemas de organización ("propias de un crecimiento acelerado") y de conducción como responsables de la crisis ${ }^{15}$.

Una reunión en la Secretaría de Industria celebrada en abril de 1966 reveló hasta donde los organismos oficiales comprometidos tenían posiciones homogéneas. Los bancos oficiales (el Banco de la Nación, el Banco de la Provincia de Buenos Aires y el BIRA) centraban su interés en la recuperación de los créditos que habían otorgado, aunque su postura era favorable a una refinanciación y solución de largo aliento. La DGI y las Cajas provisionales eran al parecer más reticentes, en tanto una solución de excepción generaba un precedente difícil de sostener frente a otras empresas que también eran morosas. De todos modos, estas conversaciones fueron interrumpidas por el golpe militar de junio de 1966; en ese momento aún no se había logrado determinar con precisión el pasivo de SIAM con el Estado y con los bancos de forma tal de poder avanzar en un programa de recuperación integral.

Como señalamos, el caso de SIAM no era el único, aunque sí el más importante e influyente para que los funcionarios tomaran conciencia de los problemas que aquejaban a muchas empresas industriales y propusieran soluciones. En este sentido, la idea de crear un "organismo de recuperación" fue madurando en la Secretaría de Industria mientras se estudiaba el problema de SIAM y se advertía que algunas reparticiones estatales no adoptaban una respuesta adecuada, según los deseos del secretario, o lo suficientemente rápida como para evitar la quiebra de las empresas comprometidas. De acuerdo al proyecto de Concepción, los bancos oficiales, las cajas de previsión y la DGI extenderían certificados de deudas al nuevo ente y éste los manejaría como crédito o capital según las distintas situaciones que presentaran las industrias.

El organismo sería el único acreedor de las empresas y su capital equivalente a las deudas de las firmas que ingresaran al sistema, una especie de Instituto di Recostruzione Industriale (IRI) que podría transformar esos créditos en otros recuperables o en capital, o en partes, de modo de lograr una estabilización de las deudas. Si los créditos no eran rescatados en un determinado plazo podrían entonces ser transformados en capital; finalmente, si todo lo actuado no permitía la recuperación de la

“Entrevista a Alfredo Concepción”, 1973, en AHOITDT. 
firma era porque se estaba frente a una empresa imposible de ser rehabilitada. Pero aún llegada esa instancia final, el organismo podía, según el secretario de Industria, tornar menos drástico el proceso de liquidación manteniendo la empresa en marcha y permitiendo la absorción gradual de la mano de obra y la reubicación de los proveedores que pudieran verse afectados por el cierra de un cliente importante. La acción del organismo de recuperación proyectado suponía, además, un control estricto sobre la gestión de las empresas o su supervisión, dependiendo de la gravedad de la situación.

Es probable que este proyecto no gozara de pleno consenso en el gabinete económico del presidente Arturo Illia. El golpe militar interrumpió estas discusiones y no sabemos hasta dónde hubiera avanzado el propósito; de todos modos, el punto es importante puesto que sería rescatado tiempo después y varias de las medidas que efectivamente se implementarían tenían como antecedentes estas discusiones, y en definitiva eran formas parcialmente diferentes de encarar los mismos problemas, pero reveladoras de distintas concepciones entre quienes tenían que tomar decisiones al respecto.

\section{1. "Nuevos" problemas para la industria. Hacia la "Ley de rehabilitación"}

El cambio de gobierno dio inicio a una nueva discusión, particularmente con el primer ministro de Onganía, Néstor Salimei, inicialmente estaba dispuesto a dejar que SIAM quebrara. De hecho, en esos meses la cuestión había llegado a la opinión pública que se orientaba en ese mismo sentido: publicaciones como Economic Survey habían señalado desde una posición ortodoxa que para SIAM:

\footnotetext{
"no cabe otra solución que un concurso liso y llano de acreedores, en el cual el Estado debe actuar decididamente como el principal de ellos dejando de lado los enfermizos prejuicios que gravitan contra la liquidación de una empresa de la magnitud de SIAM por la extinción de la fuente de trabajo que pretende significar"16.
}

Pero luego Salimei presentó un proyecto que consolidaba la deuda de SIAM y de otras empresas en condiciones similares. Según Roberto Roth, uno de los principales asesores de Onganía, Economía pretendía un sistema donde se analizara caso por caso con criterios flexibles "que permitiesen acordar a unos lo que podrían negar a otros y exigir a algunos lo que no necesariamente exigirían a todos"17.

\footnotetext{
16 Economic Survey, 26 de julio de 1966, pp. 646-647.

17 Roth (1981), p. 119.
} 
La propuesta no era compartida por algunos miembros del equipo de gobierno. Al parecer éstos convencieron a Onganía de la necesidad de estipular criterios objetivos y parejos para todas las empresas y un sistema automático de incorporación que acordase a todas las mismas facilidades con los mismos plazos. El sistema debía considerarse la última oportunidad que se daría a las empresas para gozar de una extendida moratoria sobre sus deudas fiscales, sociales y bancarias. También querían que los empresarios y directivos hiciesen su contribución a la rehabilitación, comprometiendo su patrimonio personal a la par del Estado, lo que evidenciaba un fuerte recelo y dudas respecto a la gestión empresaria.

Adalbert Krieger Vasena había calificado la propuesta de Salimei como "estatista" y discriminatoria. Pero cuando asumió como ministro de Economía, a comienzos de 1967, retomó ese proyecto. Roth, quien había acercado la propuesta "equitativa", rechazada ahora por el flamante ministro, se pregunta:

“¿El liberal del llano transformado en estatista en la montaña?" "No”, responde, "sucedía sencillamente que una cosa era la rehabilitación de empresas manejada por Salimei y otra manejada por él"; [pero] "al presidente no le importaba quién ponía la pistola al pecho a las empresas. Lo que no quería eran pistolas"18.

La controversia llevaría todavía un tiempo más hasta que se definió un régimen definitivo, aún así esa misma discusión reaparecería al momento de la implementación efectiva.

Mientras tanto, el plan de estabilización de Krieger Vasena, devaluación incluida, había agravado la situación financiera de un conjunto de empresas que se encontraban endeudadas en dólares desde muchos años atrás. En efecto, las fuertes deudas contraídas durante el "período de reequipamiento", continuaron teniendo un peso decisivo en los pasivos empresariales. Si a ello se sumaba que muchas empresas tenían fuertes endeudamientos a corto plazo en moneda local, a favor de una inflación recurrente a tasas del 30\% anual, se comprenderá que al bajar el incremento de precios y resultar las tasas de interés positivas luego de muchos años también entraron a sufrir dificultades financieras. Además, los márgenes de ganancia de muchas empresas industriales se habían reducido como consecuencia del control de precios aplicado por las autoridades frente a un sostenido aumento de los costos particularmente para las empresas pequeñas y medianas.

Por otro lado, en los años previos, el sistema bancario había reducido su capacidad prestable a través de sucesivos aumentos en la tasa de efectivos mínimos, al tiempo que la inyección de medios de pagos destinada a cubrir el déficit fiscal faci- 
litaba la creación un mercado financiero extra bancario, que se movilizaba con tasas de interés más altas, al que debía recurrir una gran cantidad de firmas. La consecuencia era un desaprovechamiento de la potencialidad productiva de las empresas industriales como resultado de las restricciones crediticias. Los contemporáneos advertían una importante capacidad de producción de bienes y equipos que eran escasamente utilizados producto fundamentalmente de la escasez de financiamiento en el sistema. Pero este era sólo una parte del problema; la falta de crédito bancario y de capitales extra bancarios a intereses razonables condujo a que muchas empresas, como se ejemplificó con el caso de SIAM, recurrieran al incumplimiento de las obligaciones fiscales y previsionales. Un estudio del momento reveló que un $85 \%$ de las firmas encuestadas mantenían ese tipo de deudas por montos que representaban más del $20 \%$ de sus necesidades de financiación ${ }^{19}$.

También, persistían las malas políticas en las compras estatales, que agravaban las dificultades de las empresas proveedoras; la posibilidad de que la liquidación de las facturas se retrasase incrementaba los costos de los intereses financieros. El secretario de industria, Ángel Solá, se referiría a la falta de una política coherente y a largo plazo en las empresas del Estado, pero también advertía las malas estrategias empresariales:

“hay empresas e industrias con un coeficiente muy bajo de utilización de sus instalaciones, pero esto también merece una reflexión -y en clara alusión a SIAM continuó-Yo una vez, de manera un poco irónica, le dije a un empresario que me parecía que haberse expandido en una línea cuyo único cliente era el Estado o un empresa del Estado en la Argentina, introducía un instrumento de riesgo a su empresa muy grande"20.

Finalmente en la mirada de los contemporáneos, y en la de aquellos que debían tomar decisiones de política industrial en particular, pesaba el proceso de "desnacionalización" que se manifestó luego de la devaluación de Krieger Vasena. El fenómeno ya no comprendía la inversión de capitales extranjeros en la expansión de sus plantas o en la inauguración de otras nuevas que desplazaban en algunos mercados a las empresas argentinas, sino la compra directa de sus activos físicos, un proceso particularmente perceptible en la industria del tabaco, de autopartes y en la cesión del paquete de IKA a la francesa Renault. Para algunos sectores del gobierno no era deseable que ese proceso se viese facilitado y ampliado como consecuencia de los conflictos que atravesaban las empresas locales ${ }^{21}$.

\footnotetext{
19 "Mejor financiación para la industria", Competencia, n 2, 20 de abril de 1967, p. 11.

20 "Interpelación: la política industrial", Competencia, n 26, 19 de abril de 1968.

21 Primera Plana, n 297, 3 de septiembre de 1968.
} 
Las dificultades comentadas afectaban a muchas firmas y de hecho los quebrantos (quiebras, convocatorias y concursos civiles) se habían incrementado en el transcurso de 1967 y superarían holgadamente los valores del crítico año de 1962 en el bienio siguiente. Pero el caso más atendible era sin dudas el de la empresa SIAM Di Tella que se encontraba cercana a la convocatoria de acreedores; la urgencia era tal que no podía esperarse el consenso en el gabinete de gobierno, más cuando el caso había tomado estado público y la posibilidad de actuar discriminatoriamente comenzaba a tornarse costosa no sólo para ciertos organismos estatales como la DGI sino también políticamente.

Las fluidas conversaciones que los dirigentes de SIAM y otras pocas empresas mantenían con funcionarios del BIRA terminaron por rendir frutos. Esa institución se transformó en un verdadero promotor de un sistema de apoyo financiero a sus clientes. En primer lugar instrumentó en 1966, previa consulta a las entidades empresarias - y a los propios directivos de SIAM - un régimen de créditos a través de debentures para asegurar la refinanciación a más largo plazo de pasivos de arrastre y en particular para hacer frente a los avales vencidos de los créditos tomados por las empresas en el exterior. Inicialmente se estudió en atender preferentemente a empresas con una estructura financiera sana, pero luego se hizo extensivo a una gran cantidad de industrias que solicitaban acogerse a ese régimen para refinanciar todo tipo de deudas; bajo este sistema se entregaron hasta 1970 más de 130 millones de dólares a unas 470 empresas.

En los primeros meses de 1967, mientras el nuevo sistema de ayuda se desarrollaba, Emilio Van Peborgh, presidente del BIRA, se reunió con el secretario de Industria para manifestar su preocupación ante la crítica situación en que se encontraban una cantidad importante de empresas. En su opinión, muchas firmas estaban sufriendo aún las consecuencias de la crisis de comienzos de los años sesenta, y era necesario auxiliarlas mediante una suerte de concordato de deudas con sus acreedores del sector público 22 .

Primero se pensó en convocar a un grupo de entre quince y veinte firmas de gran magnitud para aplicar el régimen; más tarde se decidió que, para evitar suspicacias, era preciso instaurar un criterio de selección abierto. Finalmente, en noviembre de 1967 un escueto Decreto Ley 17.507 estableció un régimen de ayuda especial para empresas con problemas financieros. Esa norma facultaba al Poder Ejecutivo a arbitrar soluciones tendientes a recuperar empresas que se encontrasen en "virtual estado de cesación de pagos" o que tuvieran dificultades financieras que sólo pudieran ser resueltas mediante disposiciones excepcionales del poder público. Quedaban incluidas especialmente las empresas que, por su "preponderancia

“Rehabilitación, la amarga espera", Primera Plana, 17 de septiembre de 1968, p. 21. 
social, su envergadura económica, su desarrollo tecnológico o su influencia en la economía nacional, regional o zonal se consideraba conveniente asistir"23. El régimen preveía fundamentalmente la consolidación de pasivos fiscales y previsionales de las firmas en problemas, que además podían ser eximidas total o parcialmente del pago de intereses, recargos y multas por mora en el cumplimiento de aquellas obligaciones. Se especificaba que el ingreso de las empresas al sistema implicaba su "sometimiento" al control del gobierno en la forma y modo en que éste dispusiera según los casos.

Luego de unos meses, en los que se discutió fuertemente los alcances e instrumentos que tendría la ley, un nuevo decreto en abril de 1968 creó una Comisión Asesora Especial (CAE) presidida por el subsecretario de Finanzas y el subsecretario de Bienestar Social, a los que se sumaban cuatro funcionarios designados por las Secretarías de Estado de Hacienda, Industria y Comercio y Seguridad Social y Trabajo. Al BIRA se le reservaba la secretaría de la Comisión y la asistencia técnica y administrativa $^{24}$. Allí quedaron definidas las obligaciones de las empresas: presentar el contrato social, la nómina de directores, socios o propietarios y la manifestación de bienes de cada uno de ellos; un detalle de las deudas con indicación de los acreedores, montos vencimientos, etc. y la individualización de los bienes gravados; una propuesta de plan de pago para el cumplimiento de las obligaciones previsionales e impositivas y la manifestación expresa de realizar aporte adicional de capital y el monto y modalidades de su integración. De todos modos el principal problema de la Comisión era que no tenía ninguna pauta política para tomar decisiones. Pavesi señaló con claridad ese problema político:

“Qué hace el Estado con las empresas que pueden ser de interés nacional, o no, porque no se sabe; en un sistema absolutamente liberal la empresa tiene que morir... Pero, en el sistema intermedio que vivíamos, ¿qué hace el Estado? A esta gente (los funcionarios de la Comisión) nadie le deba indicaciones... no existía una planificación... que diga cuáles son las áreas de más importancia para el gobierno, hasta qué punto el gobierno quiere intervenir a la actividad privada, cuáles son las funciones del Estado para regular el mercado a través de ese tipo de empresas o no; cuál es la función social del Estado, es decir, si el Estado quiera dar ocupación a través de las empresas deficitarias o quiere despedir a los obreros... hay una serie de cosas que son definiciones políticas"25.

\footnotetext{
23 Poder Ejecutivo Nacional (PEN, en adelante), Decreto Ley 17.507/67.

24 PEN, Decreto 1.768/68.

25 "Entrevista a Pedro Pavesi", julio de 1973, en AHOITDT.
} 


\section{Los dilemas del régimen de rehabilitación}

Las alternativas vinculadas a la evolución del régimen, las redefiniciones y renegociaciones de los contratos ilustran acerca de los límites del proyecto de rehabilitación así como respecto a sus resultados. La masiva recepción de la propuesta por parte de las empresas es un primer dato insoslayable. Trescientas setenta y un empresas se presentaron con el objeto de ser incluidas en el nuevo sistema, un número similar al que había accedido al régimen de suscripción de debentures pocos años antes; como dato significativo ciento sesenta y una cotizaban en bolsa, cantidad que representaba más del 30\% del total de empresas registrado en ese mercado. La suma de los capitales de las empresas interesadas superaba los 680 millones de pesos y sus ventas alrededor de 1.500 millones. Se estimaba además que las deudas totales de las empresas en condiciones de acogerse al régimen ascendían a 1.440 millones de pesos, mientras que las obligaciones previsionales e impositivas representaban casi la tercera parte de ese total. De acuerdo con las presentaciones, los rubros industriales más afectados eran el metalúrgico y el textil, entre ambos incluían al 50\% del total de postulantes, aunque prácticamente había empresas de todas las ramas industriales.

El carácter abierto que tomó el régimen finalmente impediría la toma de decisiones rápidas y daría inicio a un largo y farragoso proceso de estudios económicos y contables en un marco donde escaseaban las definiciones respecto a la política a adoptar, lo que se conjugaría además con nuevos decretos complementarios y cambios constantes en la composición de los órganos de decisión. Además, la misma vaguedad de las disposiciones no haría más que retrasar la instrumentación de las medidas. Los miembros de la Comisión debieron considerar, por ejemplo, qué se entendía por empresas en virtual cesación de pagos o por problemas financieros, o cómo determinar la gravitación económica, social o tecnológica de una firma, todos aspectos incluidos en la normativa.

Las autoridades habían señalado cuando salió la ley, en noviembre de 1967, que iba a ser aplicada de manera inmediata como correspondía a una medida considerada excepcional. Pero la idea original, que preveía una acción rápida y concentrada en pocas empresas quedó sepultada bajo el peso de los expedientes administrativos y las indefiniciones. El estudio de los antecedentes de los solicitantes fue engorroso y dilatado.

Algunas de las solicitantes entraron en convocatoria de acreedores, como Kraft, y cesaron en sus actividades, otras fueron socorridas por capitales extranjeros que finalmente se quedaron con el control de la firma (Piccardo). La situación preocupaba a los impulsores del régimen pero las trabas administrativas derivadas en parte de la presencia de diferentes opiniones en el seno de la estructura estatal impedían un accionar presuroso. 
Las empresas aspirantes, esto es aquellas que aun no estaban incluidas efectivamente en el régimen, podían pedir un certificado que les facilitaba el acceso al crédito bancario, sin necesidad de cumplir con el requisito de estar al día con las cajas nacionales de previsión. Esos certificados que, ante la demora de la sanción definitiva del régimen, servían además para realizar gestiones como la inscripción en registros aduaneros y cambiarios o solicitar autorización para cotizar acciones, se convirtieron en el objetivo inmediato de las firmas ${ }^{26}$. Inicialmente la ley no previó ningún tipo de apoyo crediticio especial en favor de las empresas que entraban bajo el régimen de rehabilitación. Pero la CAE pronto llegó a la conclusión que en algunos casos la sola consolidación de las deudas impositivas y previsionales no sería suficiente para lograr los objetivos perseguidos. Precisamente la situación financiera delicada en la que se encontraban hacía en extremo difícil que pudiesen contar con créditos bancarios, apoyo que además se veía limitado como consecuencia de la misma ley. En efecto, las garantías que debían tomarse para respaldar las deudas consolidadas comprometían el patrimonio de las empresas de forma tal que era imposible que obtuvieran ayuda bancaria ordinaria. Este problema, advertido por la Comisión, motivó una reunión en la que participó el ministro de Economía, el vicepresidente y gerente general del BCRA, y los directivos del BIRA. En esa reunión quedó convenido que el BIRA por su especialización técnica sería el encargado de prestar el apoyo financiero extraordinario a las empresas a ser rehabilitadas. Los montos no saldrían de las disponibilidades del BIRA sino de fondos que aportaría el BCRA. Pero ello se transformaría pronto en un gran problema.

En junio de 1969 el BCRA procedió a entregar 80 millones de pesos en carácter de "adelantos especiales" al BIRA. La medida resultaba inaceptable para el BIRA, pues al tratarse de adelantos debía reintegrarlos a su vencimiento independientemente del cumplimiento que observaran las empresas beneficiarias. Según los funcionarios ello resultaría injusto, por cuanto aún adoptando los mayores recaudos, la acción a desarrollarse partía del principio de tener que dejar de lado condiciones crediticias normales que no podrían aplicarse frente a la comprometida situación financiera de las firmas en rehabilitación. La propuesta era que los fondos fuesen suministrados al BIRA en fideicomiso a fin de que pudiera colocarlos en la medida más adecuada de acuerdo a la situación financiera de las empresas beneficiarias pero sin asumir mayores riesgos 27.

Luego de algún intercambio de misivas, el BCRA acordó al BIRA un adelanto de hasta 150 millones de pesos con el propósito de ser otorgados a plazos ajustados a las posibilidades de reintegro de cada empresa con amortizaciones semestrales.

\footnotetext{
26 "Rehabilitación: un traje a medida pero apretado", Competencia, 37, 11 de noviembre de 1969.

27 "Memorandum", 24 de julio de 1969, en Archivo del Banco Nacional de Desarrollo (ABND), BIRA, Expediente nro. 114.394, fs. 3-5.
} 
Mientras tanto, la crisis política luego del levantamiento popular y sindical conocido como el "Cordobazo" se agudizaba. En agosto de 1969 el presidente de la Nación Juan Carlos Onganía consultaba al nuevo ministro de Economía, José María Dagnino Pastore, respecto a la mejor alternativa de solución al conjunto de 138 empresas que habían firmado convenios y a otras 45 que eran calificadas como casos especiales. De algún modo la vieja disyuntiva que existía al comienzo de su gobierno en torno a apoyar selectivamente a un grupo de empresas o implementar un régimen uniforme reaparecía ahora en el momento de la instrumentación concreta, puesto que era el gobierno quien tenía que autorizar los convenios celebrados por decreto. Para esos 45 casos especiales se determinó que no se hicieran disposiciones uniformes sino que se contemplara "con elasticidad" cada situación ${ }^{28}$.

Meses después el BIRA sancionó un Régimen Crediticio Extraordinario para la Rehabilitación de Empresas Industriales y Mineras que complementaba las medidas que en materia de deudas impositivas y previsionales habían sido adoptadas por el gobierno a través de la ley 17.507. El apoyo financiero tenía las siguientes prioridades: 1) preservar la fuente de trabajo; 2) mantener la unidad económica en producción; 3) posibilitar la recuperación de las acreencias del Estado, tanto sea por los créditos e impuestos, contribuciones y aportes adeudados; y 4) ordenar la gestión empresaria a los fines de su normal encauzamiento.

La reglamentación, que se combinaba con lo establecido en la Ley 17.501, imponía condiciones y restricciones importantes a la gestión empresarial. Las exigencias incluían variables como la regularización de sus obligaciones impositivas y previsionales, condición indispensable para la obtención de préstamos "rehabilitadores"; la aceptación y ejecución de todas las medidas de organización o reestructuración que el BIRA considerase necesarias para asegurar la "buena marcha futura" de la firma; la aceptación de veedores permanentes con amplias facultades de fiscalización, etc. Los acuerdos caducarían automáticamente si las empresas dejasen de pagar sus obligaciones previsionales o impositivas El incumplimiento de estos requisitos traería aparejada la rescisión del convenio y la exigencia de la devolución inmediata de los préstamos, lo que implicaba seguramente la quiebra de la empresa o un cercenamiento notable de la capacidad de gestión privada.

Pronto las solicitudes fueron mayores a las disponibilidades incluso ampliadas otorgadas por el BCRA. En efecto, se recibieron 187 solicitudes de crédito (correspondientes al total de empresas incorporadas al régimen) por un monto superior a los 290 millones de pesos, prácticamente el doble de lo adelantado por el BCRA; según funcionarios del BIRA, ese monto alcanzaba para promover la rehabilitación

"Nota del Secretario General de la Presidencia de la Nación al Ministro de Economía”, 27 de agosto de 1969, en Archivo del Banco Nacional de Desarrollo (ABND, en adelante), BIRA, Expediente nº. 114.394, f. 19. 
del total de las empresas incluidas si se exceptuaba el pedido de las cuatro mayores que alcanzaban los 70 millones de pesos en total: Siam Di Tella (43 millones de pesos), La Emilia SA (12 millones de pesos), Industrias Llave SA (5 millones de pesos) y La Bernalesa SA (10 millones de pesos). La situación obligaba a pedir mayores disponibilidades al BCRA y a graduar los préstamos al conjunto de empresas afectadas que, en tanto eran aprobados por el Ejecutivo los convenios firmados a comienzos de 1970, se quejaban de las demoras en la aplicación de un régimen impulsado tres años antes con carácter de urgencia. El BIRA solicitó unos 50 millones de pesos extras al BCRA aduciendo que el adelanto anterior estaba orientado a las pequeñas y medianas empresas y que el nuevo monto se utilizaría para atender "una serie de proyectos de gran importancia económico-social, como también algunas actividades industriales que el Gobierno Nacional desea promover"; pero el BCRA desestimó el pedido a pesar de la insistencia del BIRA, señalando que el monto entregado era definitivo y que debían distribuirse esos recursos entre todas las empresas comprendidas en el régimen ${ }^{29}$. Ello suponía una virtual desnaturalización del sistema ideado, argumentaban los funcionarios del BIRA, en la medida en muchos casos la ayuda a suministrar no sería suficiente para lograr la efectiva rehabilitación de las firmas. Finalmente el BCRA amplió el adelanto a 212 millones a mediados de $1971^{30}$.

Pese a todas las indefiniciones y trabas burocráticas comentadas, más de ciento ochenta empresas terminaron por firmar convenios sobre la base de la ley 17.507 aprobados por decretos del gobierno a partir de 1970, aunque en su mayoría habían recibido créditos transitorios por parte del BIRA desde 1969. SIAM selló finalmente su acuerdo en febrero de 1970. El presidente de SIAM señaló que las pautas aprobadas por la Comisión de Rehabilitación "no prevén todo lo solicitado por la empresa [pero] el Directorio ha considerado conveniente manifestar su aceptación y pedir por lo tanto se acelere la firma del contrato respectivo". En esencia, el convenio permitía consolidar deudas fiscales y sociales que se transformaban en acciones preferidas a 15 años por unos 24 millones de dólares del momento ${ }^{31}$.

La acentuación de la violencia política y de la embestida sindical provocó en junio de 1970 el reemplazo de Onganía por el general Roberto Levingston. Pocos meses después, cuando asumió Aldo Ferrer como ministro de Economía, la "variante nacional desarrollista" que nunca había dejado de estar presente en las discusiones de política industrial en años anteriores se profundizó. El BIRA fue transforma-

\footnotetext{
29 "Nota del BCRA al BIRA", 25 de febrero de 1970 en ABND, BIRA, Expediente n 114.394, fs. 95-100 y 180186.

30 "Nota del secretario de Industria y Comercio Interior al pte. del BIRA", 25 de noviembre de 1970 en ABND, BIRA, Expediente $n^{\circ} 114.394$, fs. 137-140.

31 "Convenio Ley 17.507", en ABND, Expediente $n^{\circ}$ 185.245.
} 
do en el más ambicioso y laxo Banco Nacional de Desarrollo (BND, en adelante) y en su interior se creó un Instituto de Promoción, Reconversión y Rehabilitación Industrial y una Gerencia de Rehabilitación encargados entre otras cosas de la administración del Estado en empresas industriales y de la transformación y fusión de empresas, tal como esperaban los directivos de SIAM que sucediera ${ }^{32}$. Esta medida implicó que no sólo se atendieran las empresas efectivamente acogidas a la reglamentación sino también un número importante de firmas que atravesaban por diferentes dificultades y, según el criterio de la institución, eran dignas de ser "rehabilitadas". En otras palabras, el BND extendió por intermedio del Instituto de Rehabilitación la acción crediticia preferencial a un número aún mayor de empresas que el previsto por las disposiciones oficiales y que presurosamente se disponían a demandar créditos. Entre los numerosos casos de firmas que no fueron acogidas a la ley 17.507 pero incorporadas a los beneficios "rehabilitadores" por parte del BND se encontraban La Cantábrica, CEPSA y Atma. Es decir aquellas empresas con problemas, que no pudieron legalmente acogerse al régimen o que no lo hicieron inicialmente, fueron en muchos casos atendidas por el BND a través de un sistema similar al establecido por ley. Más tarde, en 1971 cuando la estabilidad macroeconómica del gobierno de Onganía era ya solo un recuerdo y la inflación volvía a castigar a las empresas, se facultó al Instituto de Rehabilitación del BND para llevar a cabo un plan de emergencia y de apoyo crediticio de carácter transitorio destinado a contemplar exclusivamente las necesidades en materia de salarios del conjunto de empresas en rehabilitación incluidas o no dentro del régimen legal.

\subsection{Aproximación a los resultados de régimen de rehabilitación}

En conjunto, la aplicación del sistema implicó la condonación de multas y recargos por 120 millones de pesos, el refinanciamiento de 175 millones de pesos de deudas impositivas y 145 millones de pesos de deudas previsionales (en total cerca de 100 millones de dólares) de unas 183 firmas. En forma adicional, el BIRA entregó dentro del programa especial 278 millones de pesos (más de 50 millones de dólares) sólo entre 1969 y 1972, cifra que representaba menos de la mitad de lo solicitado por las empresas.

A pesar de la amplitud que adquirió el régimen unas pocas firmas (las diez principales beneficiarias) concentraron la mitad de los préstamos de rehabilitación entre 1969 y 1972, entre las que descollaban SIAM Di Tella Ltda. SA (38 millones de pesos), La Emilia (11,5 millones de pesos), Industrias Llave (6,2 millones de pesos), Protto 
Hnos. (6,4 millones de pesos) y Papelera Hurlingham (7,9 millones de pesos). Por fuera de las incorporadas efectivamente pero asistidas con créditos por la Gerencia de rehabilitación del BND se destacaban La Cantábrica (36 millones de pesos), CEP SA (24,3 millones de pesos) y Plástica Bernabó (4,6 millones de pesos). SIAM además recibió otros 11,5 millones de pesos como préstamos de rehabilitación pero por fuera de lo acordado dentro del convenio ley 17.507. En el otro extremo, once empresas recibieron créditos por sumas menores a los 100.000 pesos cada una. El 80\% de las empresas incorporadas a la Ley 17.507 pertenecía al sector metalúrgico y al textil (Cuadro 1) y un porcentaje similar correspondía a empresas localizadas en Capital Federal y el Gran Buenos Aires.

De todos modos, con el correr del tiempo se evidenciarían las trabas más importantes para cumplir con los objetivos del régimen de rehabilitación. Pese al apoyo crediticio y a la condonación de deudas muchas de las empresas no lograron "rehabilitarse"; el problema era que no todas estaban en condiciones de superar la crisis. Pavesi estimó que de "ciento ochenta y pico de empresas que quedaron seleccionadas había una mitad de empresas fundidas" ${ }^{\prime \prime 3}$. La contradicción subyacente en el régimen se resolvería con una nueva legislación y con el control definitivo de las empresas por parte del Estado, aún contra su voluntad, un incremento del intervencionismo estatal "por defecto".

A fines de 1970 el Poder Ejecutivo dictó la Ley 18.832 que lo autorizó a disponer las medidas para mantener en funcionamiento, por "razones de interés público y con el fin de asegurar la paz social", a aquellas empresas que eran declaradas en quiebra $^{34}$. Las empresas, administradas por un funcionario estatal recibirían las sumas de dinero necesarias para la continuación de la actividad directamente de la Tesorería Nacional. El Estado podía recuperar esas sumas con el producido de la explotación si era factible o en el momento de la liquidación de la quiebra, pero con posterioridad a los acreedores verificados en el concurso; ésta disposición fue alterada dos años más tarde debido a la importante ayuda que el Estado había brindado a las sociedades. Siete de las empresas que estaban bajo la ley de rehabilitación fueron incorporadas al régimen del decreto 18.832 de modificación de la ley de quiebras y continuaron funcionando bajo ese marco legal, en la mayoría de estos casos se trataba de empresas que eran consideradas no viables desde el punto de vista productivo pero que se consideraba debían seguir en funcionamiento para evitar problemas sociales (Cuadro 2).

\footnotetext{
33 "Entrevista a Pedro Pavesi", julio de 1973, en AHOITDT.

34 PEN, Decreto $18.8832 / 70$.
} 


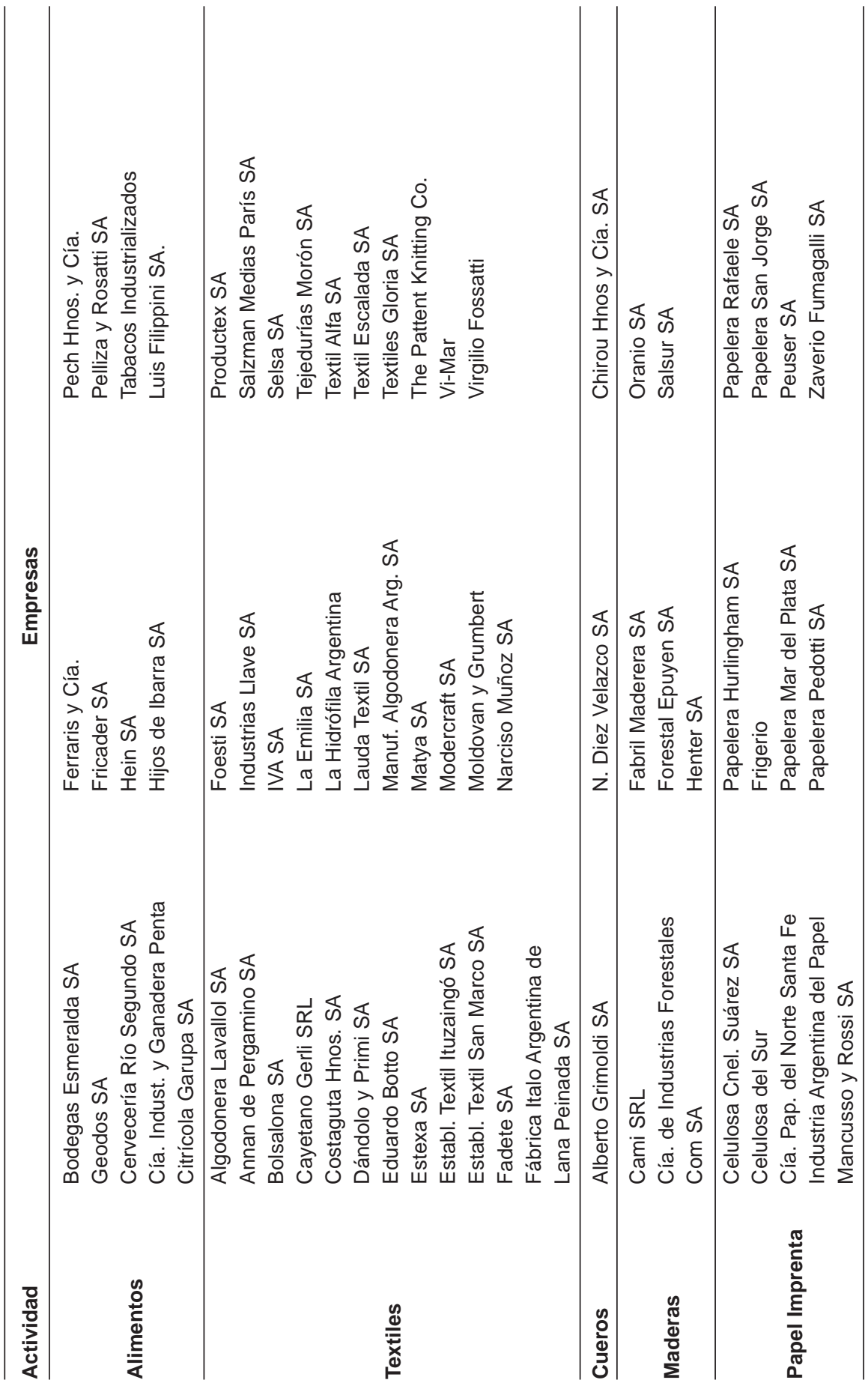




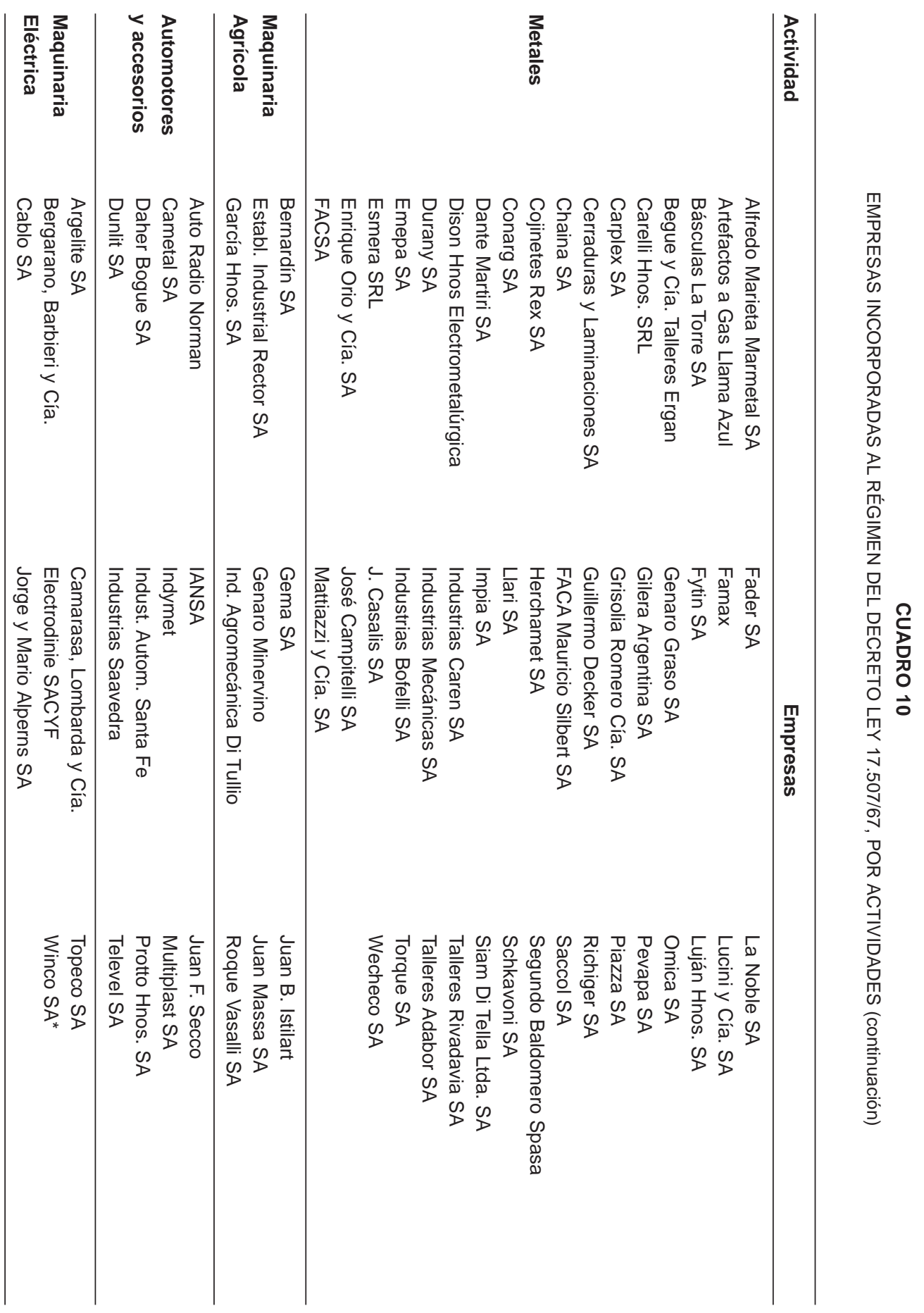




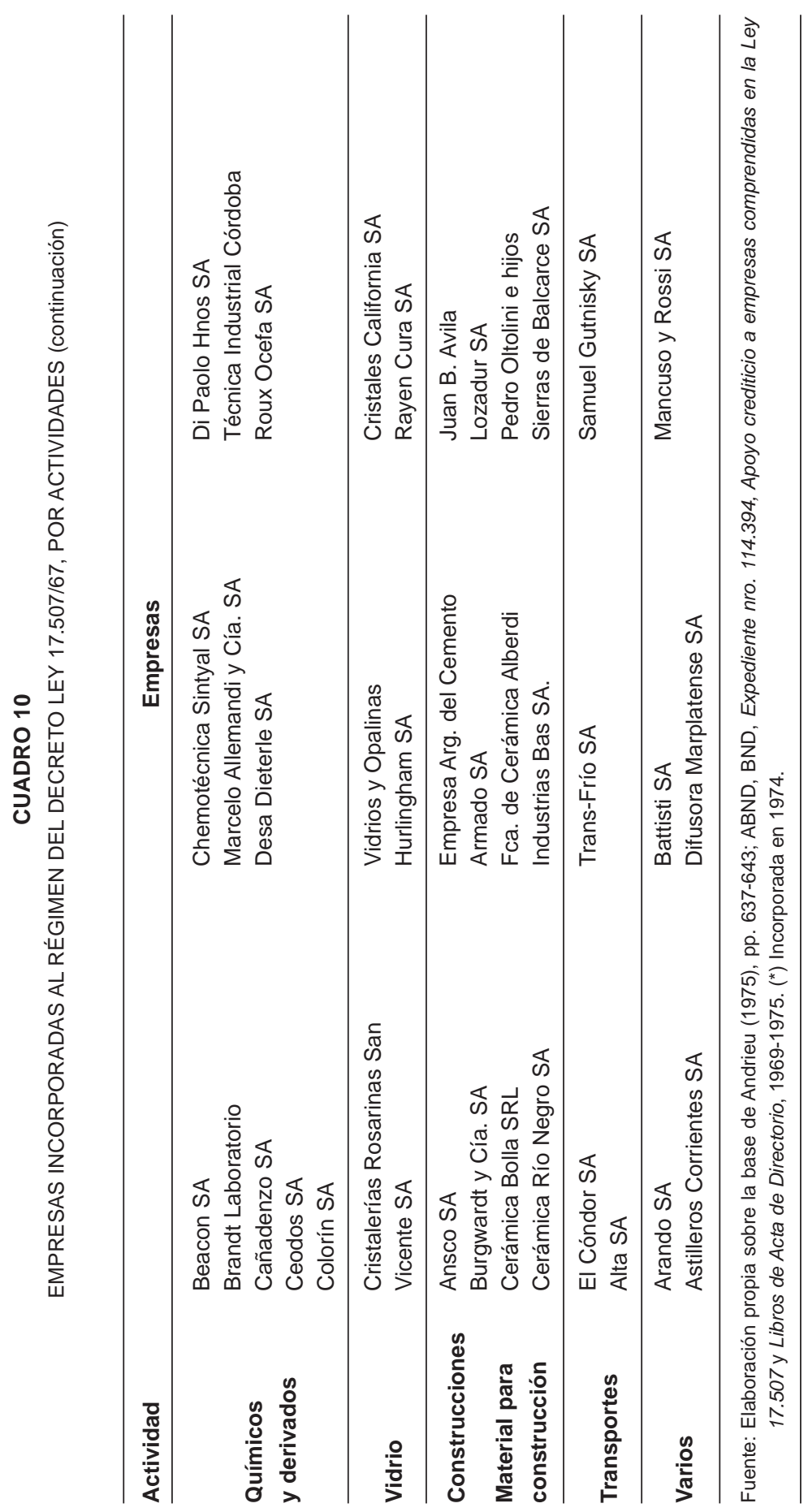




\section{CUADRO 2}

EMPRESAS INCLUIDAS EN EL RÉGIMEN DEL DECRETO LEY 18.832, AGRUPADAS POR ACTIVIDAD

\begin{tabular}{lr}
\hline Empresa & \multicolumn{1}{c}{ Actividad } \\
\hline Cía. Swift de la Plata SA & Frigorífico \\
Editorial Codex & Imprenta \\
CAT - La Florida, La Trinidad y Santa Rosa & Ingenio \\
Gilera Argentina * & Maquinaria \\
CADDIE SA & Maquinaria \\
Electrodinie SACyF * & Maquinaria Eléctrica \\
Ferrodúctil SA & Metales \\
FACA Mauricio Silbert SA * & Metales \\
Pol SA & Metales \\
Cía. Papelera del Norte de Santa Fe * & Papel \\
Mancuso y Rossi * & Papel \\
Hilanderías Luján & Textil \\
La Bernalesa SRL/Gaby Salomón SA & Textil \\
Fábrica Italo Argentina de Lana Peinada * & Textil \\
Textiles Gloria SA * & Textil \\
Textiles Viedma SA & Textil \\
\hline
\end{tabular}

Fuente: Elaboración propia sobre la base de Andrieu (1975).

Nota: $\left(^{\star}\right)$ Empresas que estaban previamente incluidas en la ley 17.507.

A mediados de 1971 una evaluación del régimen de rehabilitación mostraba que sólo el 20\% de las empresas cumplía con las obligaciones pactadas, mientras que el resto tenía una deuda atrasada de 25 millones de pesos (unos 5 millones de dólares); en diciembre la deuda ascendía al doble y en muchos casos no se estaban cubriendo las nuevas obligaciones que surgían. Los organismos estatales acreedores imponían mayores controles a las empresas y denunciaban la situación al Órgano de Control creado a fines de 1970 para vigilar los acuerdos, pero éste, conformado por funcionarios de segunda categoría, no parecía estar capacitado para adoptar ninguna solución definitiva. La única alternativa frente al incumplimiento era la ejecución de las garantías y la incorporación de las empresas al patrimonio estatal. El problema además era que muchas empresas no habían hecho efectiva la formalización de las garantías.

Frente a los "casos especiales" el Estado tuvo una política de no denuncia de los convenios, aunque ello fue fuertemente debatido entre los organismos estatales intervinientes. Luego de innumerables avatares y la firma de nuevos convenios con los propietarios, el Estado pasó a tener el control de tres empresas incluidas en el régimen (SIAM Di Tella SA, La Emilia, Fabrica de Azulejos y Opalinas Hurlingham 
SA, y más tarde Winco) y tenía participación en la dirección en varias más (entre las que destacaban Papelera Hurlingham e Industrias Llave) ${ }^{35}$. Otras no incluidas formalmente pero apoyadas con créditos de rehabilitación también fueron "estatizadas" como parte de ese mismo proceso (como La Cantábrica o Plástica Bernabó). Algunos sectores de la prensa denunciaban la "desprivatización" y tendencias "nacionalistas", de directa ingerencia de los organismos del Estado por parte del gobierno militar. No obstante, otros analistas destacaban que esa estatización era el corolario de situaciones de larga data y que por lo menos en el caso de las empresas privadas argentinas "no sea querida ni por el Estado mismo"36. Finalmente otro sector de la opinión pública hablaba de "vaciamiento de empresas" por parte de los propietarios que, como señaló Schvarzer, optaban por extraer el máximo posible de beneficios líquidos, antes de dejar la planta hipotecada a los acreedores o en manos del Estado "benefactor" que se hacía cargo para resolver los problemas de empleo ${ }^{37}$.

De todos modos, más allá de la evidente lenidad por parte del sector público a la hora de hacer cumplir las obligaciones pactadas, treinta acuerdos fueron denunciados por los organismos intervinientes; se trataba en general de empresas que no presentaban perspectivas económicas al menos algo positivas independientemente de sus angustiosos problemas financieros. Como lógica consecuencia varias de estas empresas fueron a la quiebra; no obstante, ante presiones sindicales o para evitar mayores conflictos sociales el gobierno sancionó un nuevo decreto a comienzos de 1972 que establecía la llamada "Ley de Concursos", por la que los jueces podían disponer la continuación provisoria o definitiva de las empresas bajo administración del Síndico de la quiebra, y, eventualmente, de un coadministrador ${ }^{38}$.

Treinta y cinco empresas completaron sus obligaciones y fueron consideradas "rehabilitadas". De este modo quedaron dentro del régimen de la ley 17.507 ciento veintitrés empresas, de las cuales sólo cuarenta cumplían sus obligaciones dentro de márgenes aceptables de regularidad ${ }^{39}$.

El 22 de mayo de 1973 días antes de entregar el poder, el gobierno militar permitió la renegociación de los convenios no cumplidos previendo la posibilidad de constituir sociedades anónimas con mayoría estatal. Un decreto de abril de 1974 reglamentó la renegociación y permitió la inclusión de nuevas empresas en el régimen ${ }^{40}$.

Véase específicamente para el caso SIAM Rougier y Schvarzer (2006) y para La Cantábrica, Rougier (2006). El caso Winco esta relatado en Pampin (2007).

36 Juan Carlos de Pablo, "El nuevo Estado Empresario", Análisis, nro. 588, 23 al 29 de junio de 1972.

37 Schvarzer (1996), p. 234.

38 PEN, Decreto-Ley $n^{\circ} .19 .551$ del 26 de enero de 1972.

$39 \quad$ Andrieu (1975), p. 645.

40

PEN, Decreto $n^{\circ} 1136 / 74$. Winco fue una de las empresas que se incorporó al régimen de "rehabilitación" bajo este decreto; Winco SA, Memoria y Balance, 1975. 
Pocos días después se sancionó un nuevo decreto que solicitaba a la Comisión Interministerial Ley 18.832 informase cuáles de las empresas que se encontraban en quiebra y continuaban en actividad estaban en condiciones de ser liquidadas y propusiera un plan definitivo para las que no podían ser liquidadas "en virtud de las especiales condiciones jurídicas en que se hallaren", excluyendo las consideraciones sociales o económicas ${ }^{41}$. Con todo, las indefiniciones en materia de control y decisión sobre estas empresas se mantenían puesto que el decreto estipulaba la continuidad del Órgano de Control aún cuando el gobierno peronista había creado la Corporación de Empresas Nacionales; ésta tenía capacidades para crear nuevas empresas y fusionar a las existentes y contaba específicamente con una gerencia de Rehabilitación de empresas que debía incorporar a su administración las que estaban bajo control estatal (incluidas en las leyes 17.507 y 18.832) además de los paquetes accionarios minoritarios de empresas que hasta entonces estaban en poder de distintas dependencias $u$ organismos oficiales ${ }^{42}$.

La creación de la CEN no supuso necesariamente una mayor intervención estatal ni constituía un avance en el proceso de "nacionalización" derivados de los fundamentos "doctrinarios" del peronismo, aun cuando vastos sectores de la prensa así lo presentara. Muy por el contrario, en la mayoría de los casos se trataba como destacamos de procesos de larga data que el peronismo sólo recogió a regañadientes y que agudizaba los problemas presupuestarios del Estado. El ministro José Gelbard había sostenido al inicio de su gestión que las 170 empresas que el Estado tenía bajo su administración, como consecuencia indirecta de la legislación en materia de quiebras comerciales, serían devueltas a la actividad privada para que ésta reasumiese su conducción ${ }^{43}$.

La idea de limitar la participación empresarial del Estado se acentuaría durante la gestión del ministro de Economía Alfredo Gómez Morales y más aún con la de Celestino Rodrigo, que para fundamentar su posición no recurría a los argumentos doctrinarios del liberalismo sino que se refería a los problemas fiscales ocasionados:

“Para las empresas privadas deficitarias que han pasado a la órbita del Estado deberá encontrarse una solución que haga desaparecer la carga fiscal que ellas sindican. Esta solución no deberá afectar el nivel de ingreso de los trabajadores que ellas ocupan y tampoco significa ni pretende la privatización de los servicios fundamentales que han sido nacionalizados o que siempre han estado en manos del Estado"44.

41 PEN, Decreto $n^{\circ} 1283 / 74$.

42 PEN, Ley $n^{\circ} 20.558 / 73$.

43 "Ratifican la gestión económica", La Nación, 4 de Octubre de 1973.

44 Celestino Rodrigo, discurso del 28 de junio de 1975, citado en Rougier y Fiszbein (2006), p. 206. 
El "temor" al conflicto social y el apoyo político de los sindicatos había sido, particularmente en las delicadas circunstancias que atravesó el gobierno peronista, la razón principal del Estado para sostener financieramente a algunas empresas privadas deficitarias. El alto grado de poder que habían adquirido las organizaciones gremiales - y en especial la Unión Obrera Metalúrgica- contribuyó a definir el sostenimiento de capas altamente ineficientes del sector industrial, que sólo podían apuntar a mantener el nivel de empleo. Pero el gobierno militar iniciado en 1976 no tendría mayores recaudos sobre el nivel de empleo y los problemas sociales que la quiebra de empresas importantes podía ocasionar. Tampoco el nuevo gobierno rescataría el proyecto de la CEN en tanto no pretendía reestructurar al sector industrial sino avanzar hacia la privatización de las empresas estatales y hacia la desarticulación del entramado industrial básicamente determinado por una lógica política.

\section{Conclusiones}

La crisis de 1962-1963 provocó una brusca caída del PBI, cambios en los precios relativos, inflación, falta de indicadores reales de la marcha de las empresas y tasas de interés muy elevadas y fluctuantes; a ello se agregó la incapacidad del sector público para programar sus compras u orientarlas hacia las compañías locales. Luego de la crisis gran cantidad de empresas industriales sufrieron dificultades financieras y económicas mientras el sector en su conjunto iniciaba el mayor período de crecimiento ininterrumpido de su historia y alcanzaba niveles de eficiencia y maduración destacados. Con el propósito de responder el porqué de las dificultades de las empresas pueden presentarse de manera esquemática dos perspectivas de análisis. La primera destaca los factores internos a la empresa. Si una empresa quiebra finalmente la responsabilidad siempre debe ser adjudicada al empresario, en tanto se equivocó a la hora de analizar el mercado, de evaluar la tasa de retorno esperable, estimó erróneamente la relación necesaria entre las máquinas y la mano de obra, etc. Frente a una situación de esta naturaleza, desde este enfoque sería deseable que la empresa no siga operando de manera ineficiente la actividad productiva, desperdiciando recursos. Con la liquidación y venta de sus activos, éstos podrían pasar a empresarios más capaces que utilizaran mejor las instalaciones y que la mano de obra fuese absorbida por el mercado en empleos más productivos. En otras palabras, la racionalización del sector productivo se logra a través de las crisis, en las que perecen los emprendimientos más ineficientes producto de errores de la conducción empresaria (sean estos de gestión, organización, comercialización, financieros, tecnológicos o productivos). 
Si la mirada recala en los factores externos, las quiebras se explican esencialmente por el entorno macroeconómico y en particular por las políticas económicas implementadas desde el Estado, por ejemplo, políticas monetarias restrictivas, o por las modificaciones constantes de las "reglas de juego". Este enfoque tiene como trasfondo un diagnóstico que entiende a la crisis de las empresas como producto de una situación "transitoria" en tanto fue generada por los cambios en el contexto macroeconómico, y financiera más que económico-productiva; mientras que el enfoque clásico considera que los problemas financieros son consecuencia de los desajustes económicos de las firmas. El punto es importante porque en el segundo caso el Estado estaría obligado moralmente a reparar los problemas coyunturales que sus medidas provocaron sobre una estructura empresaria básicamente sana y con un potencial desarrollo productivo intacto.

Si bien estos enfoques son necesariamente compendiados y el proceso histórico siempre es mucho más complejo, es evidente que la crisis de muchas empresas puede explicarse principalmente por causas internas y otras muchas por causas externas. Pero la causa específica de la crisis empresaria no es el objeto de análisis de este trabajo sino la respuesta en materia de política económica que los diferentes gobiernos y organismos involucrados tuvieron frente a ese dilema, y los conflictos de instrumentación. Claro que, en parte, la dificultad para realizar un diagnóstico correcto y ajustado de la situación motivó las indefiniciones y la lentitud de las respuestas del Estado, en tanto era necesario realizar un examen preciso de cada caso para conocer las potencialidades económicas de las empresas y definir si debían ser liquidadas o rehabilitadas dentro de un proyecto de desarrollo industrial más ambicioso, además de considerar cierta irresponsabilidad empresarial. En otras palabras todo régimen aplicado uniformemente sería seguramente no equitativo en tanto solventaría a empresarios que habrían obrado erróneamente a la vez que a aquellos que sólo fueron afectados por los cambios del entorno económico principalmente.

De todos modos, se produjo un tránsito visible desde los problemas financieros de las empresas al problema social en la lógica de decisiones de ayuda por parte del Estado a lo largo de los años sesenta y mucho más a comienzos de los setenta; los criterios comentados resultaron relegados por la necesidad de preservar las fuentes de trabajo, independientemente de que las causas de la crisis fueran "transitorias" (financieras) o "permanentes" (económico-productivas). Ello se evidencia en la modificación de la ley de quiebras hacia 1970 y en la lenidad del sector público a la hora de denunciar los convenios no cumplidos dentro del régimen de rehabilitación.

El régimen de rehabilitación no pudo subsanar esa preexistente disparidad de visiones. La contradicción más importante era que el régimen tenía como objeto que las empresas con importancia social y económica siguiesen funcionando; en caso de incumplimiento debían anularse los beneficios, lo cual contradecía el propósito del régimen. Más aún, como destacó un analista contemporáneo, el mecanismo ideado 
suponía que el saneamiento financiero se daría con el refinanciamiento de las deudas con el Estado, solamente, y eventualmente con créditos bancarios adicionales, lo que implicaba desconocer los problemas económicos, tecnológicos y organizativos, cuya solución estaba en manos de los mismos directivos ${ }^{45}$. En rigor, lo que ocurría era que no se había resuelto una alternativa de apoyo para cada caso específico sobre la base de estudios detallados. La heterogeneidad del conjunto ponía trabas insalvables a una acción homogénea y coordinada, mucho más en un contexto de elevada incertidumbre política.

Finalmente, lo que podría denominarse una tercera posibilidad contemplaba la solución de los problemas de las industrias dentro de un proyecto de mayor intervención del Estado en las definiciones de política industrial. Para esta visión, no sólo debían sostenerse las empresas para que no quebraran, y de este modo consolidar la expansión del estado por "defecto", sino fundamentalmente incluirlas positivamente en un proyecto de racionalización, fusión o redimensionamiento que les permitiera reposicionarse frente a las de capital extranjero y por lo tanto otorgara mayores posibilidades de emprender el camino del "desarrollo económico nacional". En otras palabras, el intento de salvaguardar las viejas empresas con problemas debía asociarse a un proceso de reconversión más estructural de la industria argentina. Esta postura se evidencia en el interés siempre presente de conformar un particular IRI local durante la experiencia de Illia, retomada durante los últimos años de la gestión de Onganía y con el "giro nacionalista" de Levingston y llevada a cabo muy parcialmente con el gobierno peronista y la creación de la CEN. Las dudas, temores e indefiniciones en torno a esa propuesta y, más aún, los problemas concretos de implementación una vez definida sugieren la existencia de múltiples visiones en los funcionarios y organismos estatales, sujetos a su vez a numerosas presiones de distintos actores sociales que evidencian vetos, frenos y contramarchas finalmente negativos a la hora de definir políticas públicas coherentes en el largo plazo. Esas dificultades se agigantaban con la inestabilidad de la burocracia producto de los cambios en la cúspide del poder gubernamental en la Argentina de esos años. Los interventores, veedores $\mathrm{u}$ otros funcionarios de fiscalización en las empresas se sucedían al mismo ritmo que variaban las reglamentaciones y los administradores de los distintos y numerosos organismos públicos que intervenían en el proceso, y que no necesariamente actuaban como un conjunto único y racional.

De todos modos, la discusión inicial sobrevoló todo el período y culminó en 1976 cuando el régimen militar, menos condicionado por la conflictividad que podía desatar la quiebra de las empresas, decidió liquidar a aquellas ineficientes y en el mejor de los casos entregar los activos productivos a nuevos empresarios, con lo que, 
quizás de manera paradójica, enfatizaba en los errores de conducción de las firmas más que en las malas políticas estatales, aunque la postura finalmente era coherente con una interpretación liberal clásica.

\section{Fuentes}

Anales De La Legislación Argentina, 1958-1982.

Archivo De Historia Oral Del Instituto Torcuato Di Tella (AHITT).

Entrevistas a A. Concepción, G. Klein, Pedro Pavesi y Ricardo Zinn (1973).

Banco Industrial/Banco Nacional De Desarrollo (BND).

Memorias y Balances, 1950-1986.

Actas de Directorio, 1944-1990.

Libros copiadores de correspondencia.

Expedientes administrativos ordinarios y reservados.

Bolsa De Comercio De Buenos Aires (BCBA).

Memorias anuales, 1954-1980.

Consejo Tecnológico Del Movimiento Nacional Peronista (CTMNP).

Empresas del Estado. Corporación: ¿Sí o no?, nro. 9, Buenos Aires (1973).

Diarios: La Nación, Clarín, El Cronista Comercial, La Opinión, La Prensa, La Razón.

Fabrica Argentina De Vidrios Y Opalinas Hurlingham.

Memoria y balance, 1967-1980.

Informe de la Comisión Honoraria de Reactivación Industrial, inédito, septiembre de 1963

La Cantábrica.

Memorias y Balances, 1940-1992; Libros de Actas de Directorio, 1960-1990.

Revistas: Competencia, Economic Survey, El Político, de la Unión Industrial Argentina, Información Empresaria, Primera Plana. SIAM.

Memoria y balance, Libros de Acta de Directorio, Libros de Acta de Asambleas, 1960-1994. WINCO.

Actas de Asamblea, Actas de Directorio; Memorias y Balances, 1958-1990.

\section{Bibliografía}

ACEÑA, Pablo y COMÍN, Francisco (1990) (eds.): Empresa pública e industrialización en España, Madrid, Alianza Editorial.

—(1991): INI, 50 años de industrialización en España, Madrid, Espasa Calpe. 
AMATORI, Franco (2000): “Beyond State and Market: Italy's Futile Search for a Third Way" en TONINELLI, Pier Angelo, The Rise and Fall of State-Owned Enterprise in the Western World, Cambridge, Cambridge University Press, pp. 208-236. ANDRIEU, Pedro (1975): Empresas públicas. El rol del Estado en el crecimiento económico y el cambio social, Buenos Aires, Editorial El Coloquio.

BRAUN, Oscar y JOY, Leonard (1968): "A Model of Economic Stagnation. A Case Study of the Argentine Economy", The Economic Journal, 312, December, pp. 868887.

COMÍN, Francisco y DÍAZ FUENTES, Daniel (2004): La empresa pública en Europa: una perspectiva histórica, Madrid, Síntesis.

DIAMAND, Marcelo (1973): Doctrinas económicas, desarrollo y dependencia, Buenos Aires, Paidós.

DORFMAN, Adolfo (1983): Cincuenta años de industrialización en la Argentina, 19301980, Buenos Aires, Solar-Hachette.

EVANS, Peter (1995): Embedded autonomy. States and industrial transformations, Princeton, Princeton University Press.

FERRER, Aldo (1963): "Devaluación, redistribución de ingresos y el proceso de desarticulación industrial en la Argentina", Desarrollo Económico, nº 4, Buenos Aires, pp. 5-18.

FERRUCCI, Ricardo (1991): Política económica argentina contemporánea, Buenos Aires, Macchi.

GERCHUNOFF, Pablo y LLACH, Juan José (1975): “Capitalismo industrial, desarrollo asociado y distribución del ingreso entre los dos gobiernos peronistas: 19501972", Desarrollo Económico, n ${ }^{\circ}$ 57, Buenos Aires, pp. 3-54.

-(1998): El ciclo de la ilusión y el desencanto, Buenos Aires, Ariel.

KAPLAN, Marcos (1969): “El Estado empresario en la Argentina”, El Trimestre Económico, México, enero, pp. 69-111.

KATZ, Jorge (1967): “Características estructurales del crecimiento industrial argentino, 1946-1964", Desarrollo Económico, no 26, Buenos Aires, pp. 59-76.

KATZ, Jorge, y KOSACOFF, Bernardo (1989): El proceso de industrialización en la Argentina. Evolución, retroceso y prospectiva, Buenos Aires, Centro Editor de América Latina.

PAMPIN, Graciela (2007): "La industria argentina mirada a través del crecimiento, consolidación y decadencia de Winco, 1954-1980", en ROUGIER, Marcelo (dir.), Políticas de promoción y estrategias empresariales en la industria argentina, 1950-1980, Buenos Aires, Ediciones Cooperativas, pp. 253-290.

PREBISCH, Raúl (1963): Hacia una dinámica del desarrollo latinoamericano, México DF, Fondo de Cultura Económica.

RAPOPORT, Mario (2003): Historia económica, política y social de la Argentina, Buenos Aires, Macchi. 
ROTH, Roberto (1981): Los años de Onganía. Relato de un testigo, Buenos Aires, Ediciones La Campana.

ROUGIER, Marcelo (2004): Industria, finanzas e instituciones. La experiencia del Banco Nacional de Desarrollo, Bernal, UNQui.

-(2006): "Un largo y sinuoso camino: auge y decadencia de una empresa siderometalúrgica argentina. La Cantábrica 1902-1992", Desarrollo Económico, octubrediciembre, pp. 385-417.

ROUGIER, Marcelo y FISZBEIN, Martín (2006): La frustración de un proyecto económico. El gobierno peronista de 1973-1976, Manantial.

ROUGIER, Marcelo y SCHVARZER, Jorge (2006): Las grandes empresas no mueren de pie. El (o)caso de SIAM, Norma.

SAPELLI, Giulio y Francesca CARNEVALLI (1986): Uno sviluppo tra política e strategia, ENI (1953-1985), Milano, Franco Angeli.

TONINELLI, Pier (2000) (ed.): The rise and fall of the State Owner enterprise in the Western World, Cambridge, CPU.

SCHNEIDER, Ben Ross (2004): Business Politics and the State in Twentieth-Century Latin America, Cambridge, Cambridge University Press.

SCHVARZER, Jorge (1979): "Empresas públicas y desarrollo industrial en Argentina", Economía de América Latina, México, CIDE, nº 3, pp. 45-68.

-(1996): La industria que supimos conseguir, Buenos Aires, Sudamericana.

UGALDE, Alberto (1983): Las empresas públicas en la Argentina: su magnitud y origen. Documento de Trabajo $n^{\circ} 3$, Buenos Aires, CEPAL. 